\title{
Study on Fault and Isolated Condition in Two Circuit Configurations of PV-ESS Hybrid System
}

\author{
Myo Htaik, Ryoichi Hara, and Hiroyuki Kita \\ Graduate School of Information Science and Technology, Hokkaido University, N14W9 Kita-Ward, Sapporo, \\ Hokkaido 060-0814, Japan \\ Correspondence should be addressed to Myo Htaik, myohtaik@gmail.com
}

Received 28 December 2011; Accepted 26 January 2012

Academic Editors: E. R. Bandala and L. Ozgener

Copyright (๑) 2012 Myo Htaik et al. This is an open access article distributed under the Creative Commons Attribution License, which permits unrestricted use, distribution, and reproduction in any medium, provided the original work is properly cited.

Most photovoltaic (PV) generation systems are connected with a utility grid and recognized as supplemental generation resources; but in some applications such as microgrid concept, a PV system works as a main resource. To improve the availability of PV systems, technological development for higher less output fluctuation in normal condition, higher fault tolerance in fault occurrence, and power demand and supply balancing in isolated condition are required. For these reasons, hybridization of a PV system and an energy storage system (ESS) would become an important technology in the future. This paper presented two kinds of circuit models, conventional "ac-connected PV-ESS," and proposed "dc-connected PV-ESS" in which ESS is inserted at the dcside of PV system. This paper also investigated dc-link voltage controlled by dc-dc converter of ESS in dc-connected PV-ESS and suitable control systems are also discussed normal, during fault occurrence and isolated operation.

\section{Introduction}

Recent R\&Ds on photovoltaic (PV) generation systems and related technologies and expectation as a solution for the global warming issue accelerate PV installations in the world. PV generation systems have been installed in small-scaled application such as residential sector and in very largescaled application such as Mega-Watt class PV power plant. However, PV generation output is generally intermittent and unstable since it strongly depends on the external environmental condition such as solar radiation level and ambient temperature. Since most of PV systems are operated with a grid interconnection, fluctuations in PV output may disturb the stable power system operation and deteriorate the power quality. In some applications such as microgrid concept, a PV system works as a main source.

In order to investigate the above concerns, the New Energy and Industrial Technology Development Organization (NEDO) of Japan promoted two demonstration projects in Japan [1]. In those projects, effects of concentrated PV installations at a residential area and interconnection of a $\mathrm{MW}$-class PV power plant were investigated. Application of energy storage systems (ESSs) such as lead-acid battery and/or Sodium Sulfur (NAS) battery were also developed to improve stability and controllability of PV systems. For example, a method for suppressing the output fluctuation of PV system using NAS battery system was proposed and investigated in [2]. Furthermore, in [3], the ESS capacity required for suppressing PV output fluctuation was evaluated.

A usual PV-ESS hybrid system adopts the circuit configuration in which the PV arrays and the ESS are coupled at the ac-side through individual dc-ac inverters (called "ac connected PV-ESS hybrid system" in this paper). An advantage of the ac connection is availability of commercialized PV arrays and an ESS. Another possible circuit configuration is to connect the PV arrays and the ESS at the dc-side of a common dc-ac inverter (called "dc connected PV-ESS hybrid system" in this paper). In [4], DC connection of PVs and ultracapacitors is proposed and technological feasibility of the proposed circuit configuration is discussed through computational simulation. In [4], however, the detailed control strategy for smoothing PV power output has not been investigated. 
Behavior of PV systems against a fault occurrence is also a serious concern. From the safety perspectives, the PV systems should be stopped to avoid unintentional islanded operation [5]. On the other hand, implementation of fault ride through (FRT) function is becoming more important issue. In fact, in some countries with large amount of grid-connected PV systems, the grid code for PV interconnection requires adequate FRT function [6] in order to secure the system stability. Furthermore, generation losses during a gridside fault are a great concern of PV owner. The PV-ESS hybrid system can avoid these effects caused by a grid-side fault occurrence. Particularly, dc connection enables power exchange between the PV arrays and the ESS even when the ac-circuit is unavailable due to fault occurrence. Here, it is assumed that an ESS device is installed by PV system owners in this paper.

The experiment for operating the hybrid solar-wind system in grid-connected mode and stand-alone mode using battery storage is discussed [7]. Here, at the stand-alone condition powers from the solar-wind hybrid system and the battery power are supplied to emergency loads [7]. For technical survey, a model of ESS connected at dc side of the PCS of PV system is performed in $[8,9]$, which is a PV projects of Saijo City, Japan. It is one of the PV projects from NEDO, and it is also investigated for normal condition.

From these backgrounds, this paper focuses on the two circuit configurations of PV-ESS hybrid systems under faulted operation and isolated operation by utility grid fault. However, ideal constant voltage source is assumed as ESS system because this paper is focused on fudamental feasibility of circuit configuration and its control model. A control method for dc-dc converter in dc-connected PVESS hybrid system is proposed which can realize the PV generation output smoothing in the normal condition and the PV generation salvage under the faulted condition and effective charge to ESS in isolated condition. Moreover, in this paper performance of the two circuit configurations of the PV-ESS hybrid system is compared the fault occurrence and isolated condition. The auxiliary elements breaker $1 \& \mathrm{~F}_{1}$ and breaker $2 \& \mathrm{~F}_{2}$ are installed in the research models, but these devices did not operate at the same time. This paper considered two fault locations; a severe fault $\left(\mathrm{F}_{1}\right)$ occurred at the sending bus terminal of the transmission line, and breaker 1 is operated and case (1) to case (4) investigated in this condition. Another faulted location $\left(\mathrm{F}_{2}\right)$ occurred at the middle point of the transmission line for microgrid concept, and breaker2 is operated and case (5) investigated in this condition. Both types of circuit configuration and its control strategy are validated by computational simulations on Matlab/Simulink environment.

\section{Conventional Grid-Connected PV System}

2.1. Modeling and Control Strategy. A conventional grid-connected PV system consists of PV arrays, PWM-based voltage source dc-ac inverter (so-called power conditioner, or PVPCS), and auxiliary elements such as a dc-link capacitor $\left(C_{\mathrm{dc}}\right)$, an $L_{f} C_{f}$ low-pass filter. As is well known, the power

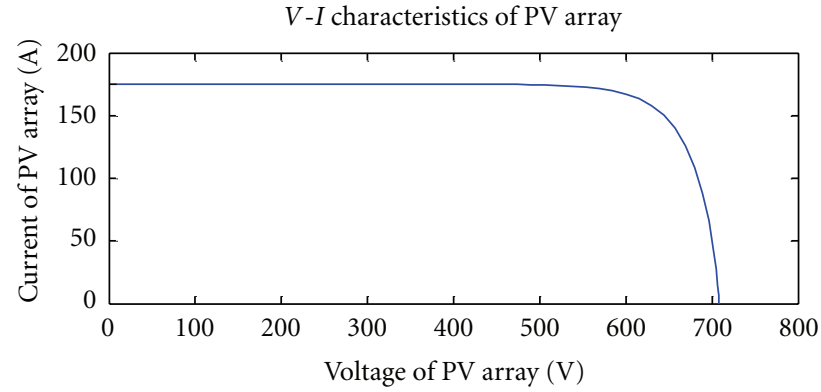

Figure 1: $I-V$ characteristic of a PV array.

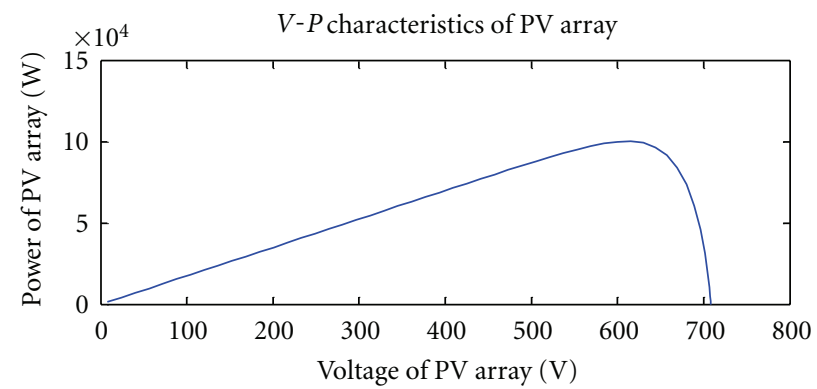

Figure 2: $P-V$ characteristic of a PV array.

generated by PV arrays depends on the terminal voltage as shown in Figures 1 and 2 (assumed rated power is 100.4 [kW] and irradiation level is $\left.1\left[\mathrm{~kW} / \mathrm{m}^{2}\right]\right)$. In order to simulate this characteristic model, as shown in Figure 3, this paper employs an ideal current source [10] whose output current is determined as a function of the terminal voltage shown in Figure 1. In Figure 3 "inv" means ac-side condition of PCS, "ac_ $g$ " means $L_{f} C_{f}$ filter output signals which is so-called acgrid side and $d$ and $q$ indicated $d$-axis and $q$-axis of the $d-q-o$ reference frames. $P_{\mathrm{PV}}$ is generated power of $\mathrm{PV}$ arrays.

Generally, the dc-link voltage is adjusted so that the maximum power can be extracted from PV array. This control scheme, well known as the maximum power point tracking (MPPT), has some variations; however, the perturbation and observation ( $\mathrm{P} \& \mathrm{O})$ method in [11] is most popular and is employed in this paper. That is, the PCS governs the dc-link $V_{\mathrm{dc}}$ voltage in a $\mathrm{P} \& \mathrm{O}$ manner. The phase-lock-loop (PLL) is also included in these research models for generating a signal in phase to ac-grid side voltage and which are providing signals for $a-b-c$ axis to $d-q-o$ axis transformation.

2.2. Behavior of Conventional Grid-Connected PV System. In this section, behavior of the conventional grid-connected PV is demonstrated based on the computational simulation of the employed PV model. Figure 4 shows the dc-link voltage and PCS converting power (measured at ac-side) under the stepwise irradiation variation (from $1.0\left[\mathrm{~kW} / \mathrm{m}^{2}\right]$ to 0.5 $\left.\left[\mathrm{kW} / \mathrm{m}^{2}\right]\right)$. As shown in this simulation result, the PCS converts and injects the adequate amount of power to the grid; this is reason why the PV generation is widely recognized as unstable and intermittent. If an ESS is equipped with the PV system, it can work to smooth the system output. 


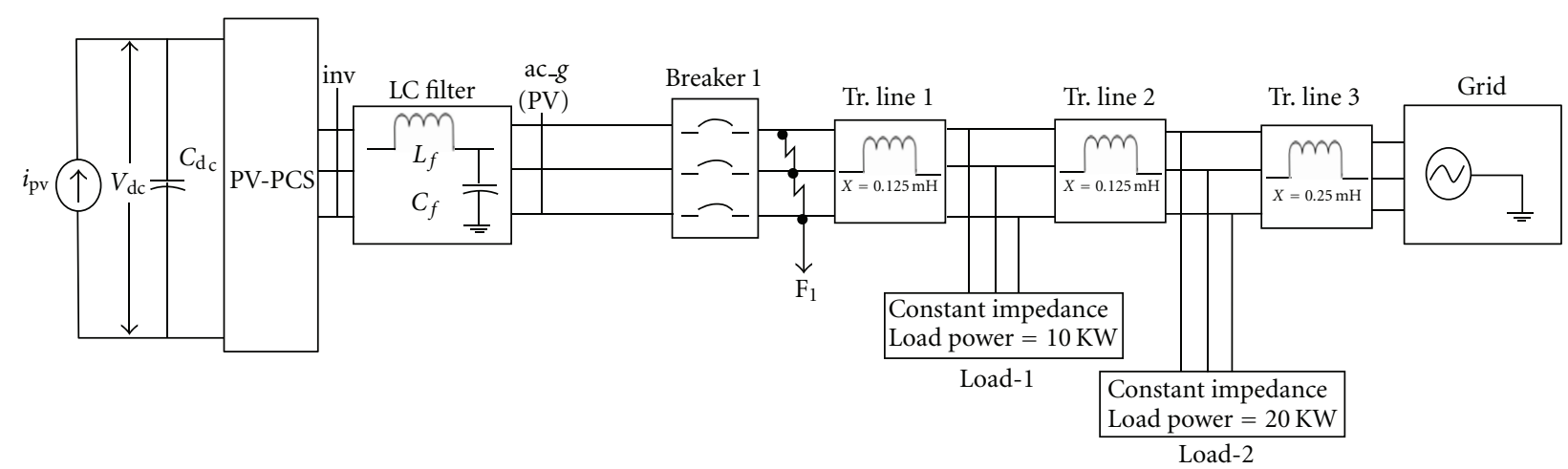

FIgURE 3: The model of conventional grid-connected PV system.

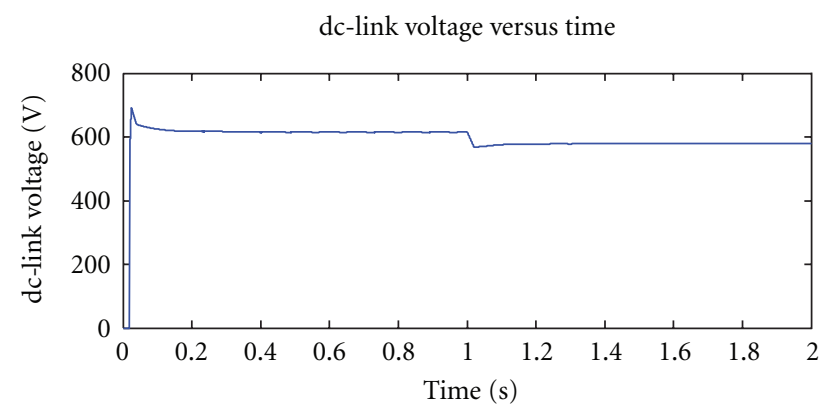

(a) dc-link voltage

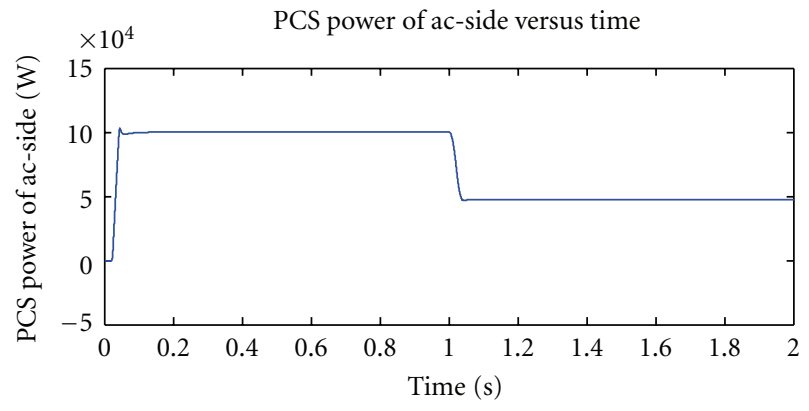

(b) PCS power (mesured at ac-side)

FIGURE 4: dc-link voltage and PCS power under a stepwise irradiation variation.

TABLE 1: Specification of PV System.

\begin{tabular}{lc}
\hline Parameters & Values \\
\hline PV output power $\left(P_{\mathrm{PV}}\right)$ & $100.4[\mathrm{KW}]$ \\
Capacitor $\left(V_{\mathrm{dc}}\right)$ & $7000 \mu \mathrm{F}$ \\
transmission line impedance & $0.5 \mathrm{mH} / \mathrm{line}$ \\
PWM carrier frequency & $11050 \mathrm{~Hz}$ \\
\hline
\end{tabular}

In this case solar radiation level changed step-wise, which is severe or too fast condition by varying of weather or environment in PV panels of PV system. In grid-connected PV system, PV-PVS was operated by conventional power and current controller in Figure 7 [10]. The PV panel's maximum output power could be specified by the MPPT algorithm. The reference reactive power was set to $Q_{\text {inv }}{ }^{*}=0$ in Figure 7 for unity power factor. The power controller was determined for reference signals which input signals for current controller. The-pulse-width-modulation-(PWM-) based dc-ac inverter (PV-PCS) was operated by controllable signals which are output from the power and current controller. The other signals in control systems are observed from inverter and acgrid side. Some specifications of the parameter and value are described in Table 1.

Figure 5 shows the behavior of PV system model under the ac-side three-phase to ground faults $\left(\mathrm{F}_{1}\right)$. Here, it is assumed that a three-phase to ground fault at sending terminal of a transmission line occurs at 1.0 [sec] and is cleared at $1.05[\mathrm{sec}]$ by tripping the breaker 0.05 [sec] after the fault occurrence. As shown in Figure 5, when a serious fault occurs at the ac-grid and the voltage at the interconnection point falls down to nearly zero, the PV-PCS loses its power conversion ability; therefore, power generated by PV arrays is charged to dc-link capacity. As a result, the dc-link voltage rises to the open-circuit voltage of the PV arrays and the power generated by PV arrays becomes zero in case (1).

\section{AC-Connected PV-ESS Hybrid System}

3.1. Circuit Configuration. A circuit configuration of acconnected PV-ESS hybrid system is shown in Figure 6; this system employs PV and ESS systems. A constant voltage source is used as an ESS, because this paper is focused on fundamental feasibility of the proposed circuit configuration. That is, the ESS is connected in parallel to the PCS for PV array (call PV-PCS in this paper) at the ac-side through the dc-ac inverter for ESS (call ESS-PCS in this paper).

3.2. Control Strategy. Under the normal condition, both PCSs are able to regulate the converting power by the individual conventional current control for a PWM-based dc-ac inverter. For the PV-PCS, the output target power (Figure 7) should be specified by the MPPT algorithm. On the other hand, the output reference should be adjusted so that the undesired fluctuation components in ESS-PCS 
dc-link voltage versus time

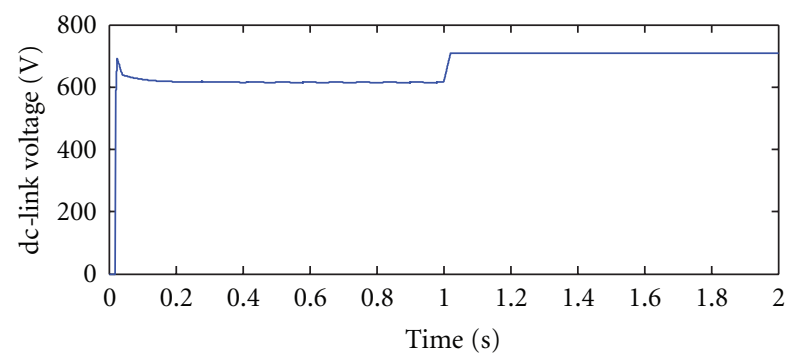

(a) dc-link voltage (case 1)

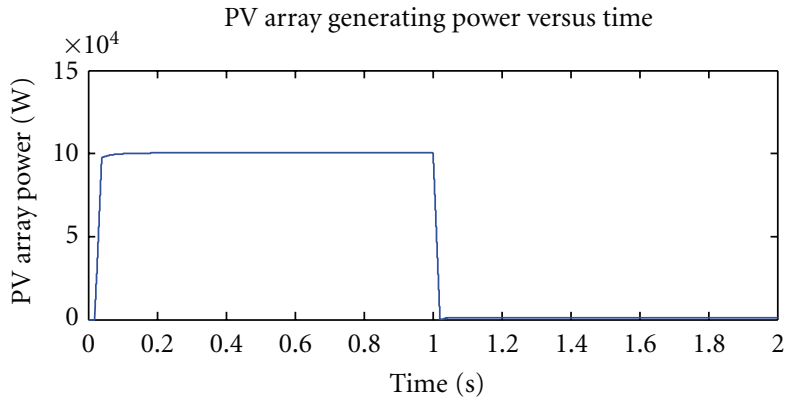

(b) PV array genertaion power (case 1)

FIGURE 5: Behavior of PV model under the fault condition.

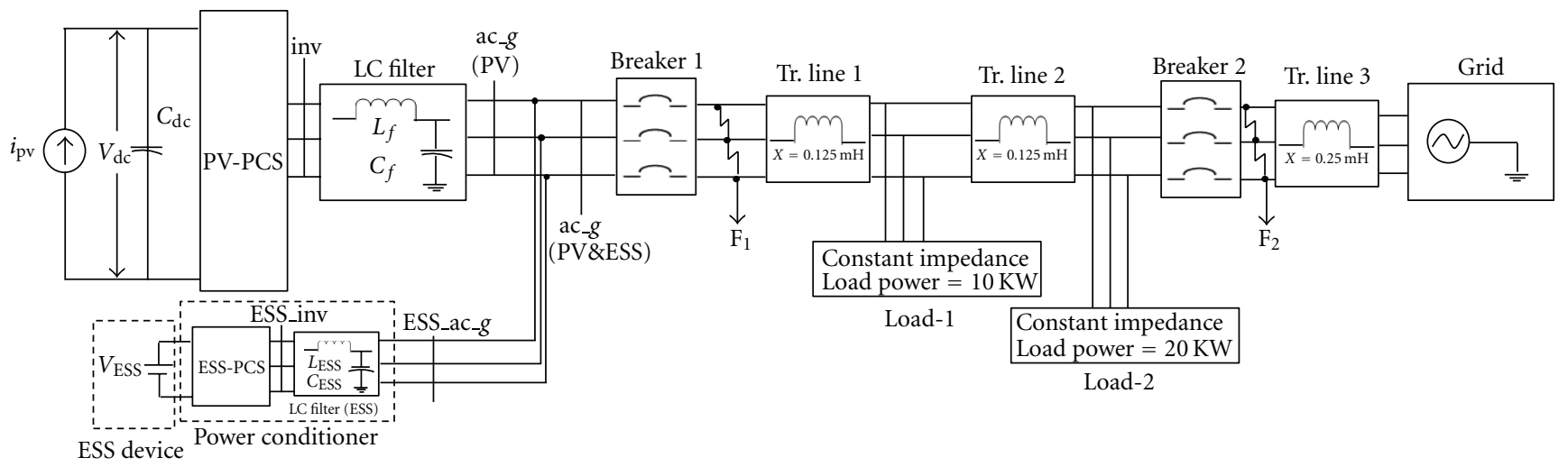

FIGURE 6: Circuit configuration of an ac-connected PV-ESS hybrid system.

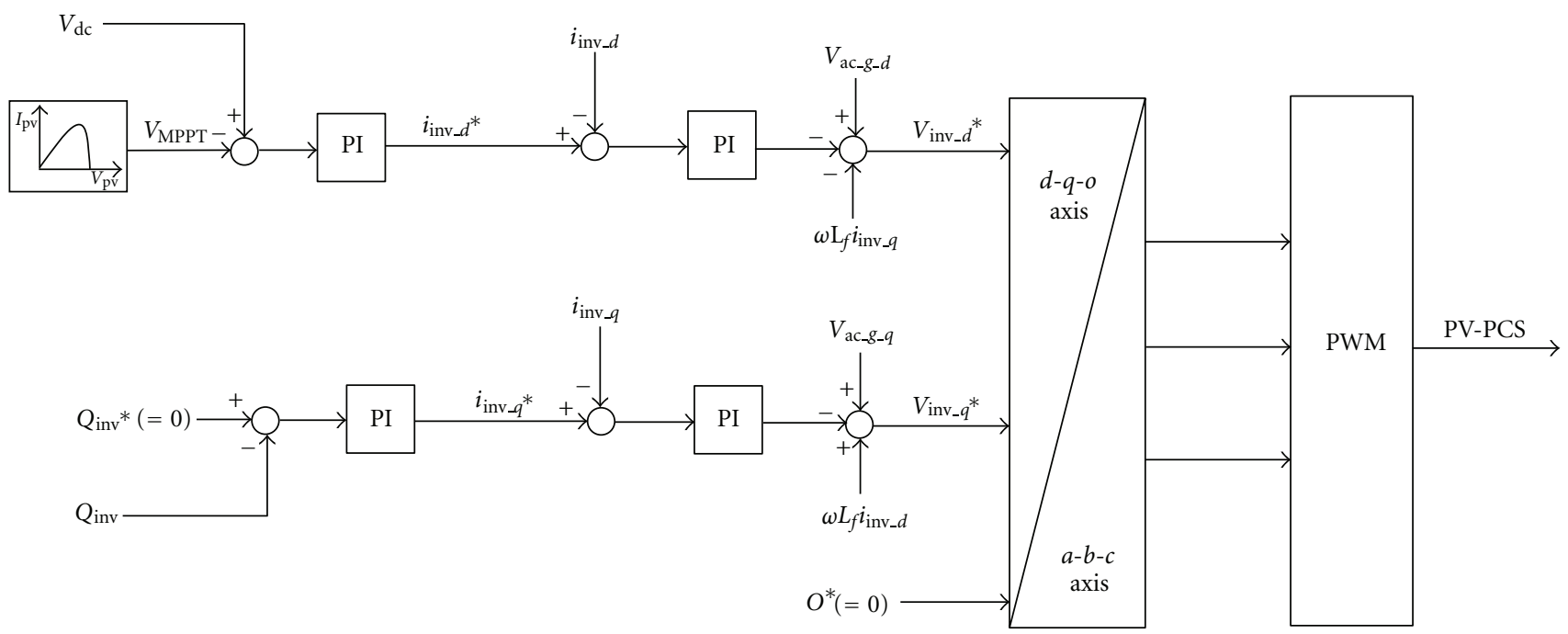

FIGURE 7: Conventional current control of a dc-ac inverter (PV-PCS).

output can be canceled. In this paper, the ESS-PCS output target is adjusted so that the system output becomes specified constant value, $P_{\text {ac } \_g}$ (PV and ESS) set $110.4[\mathrm{KW}]$, (see Figure 8) for $10[\mathrm{KW}]$ discharging power from ESS for case (2), case (3), and case (5).

When a severe three-phase to ground fault $\left(\mathrm{F}_{1}\right)$ occurred at sending terminal of the transmission line, the breaker
(Breaker1) is tripped; the PV and ESS form an isolated system. In case (2) both PCSs were operated by power and current controller results have shown that the PV power could not be charged to ESS and dc-link voltage could not be regulated after the fault occurrence.

In this isolated condition, the ESS can absorb the PV-PCS power by changing the ESS-PCS control mode from current 


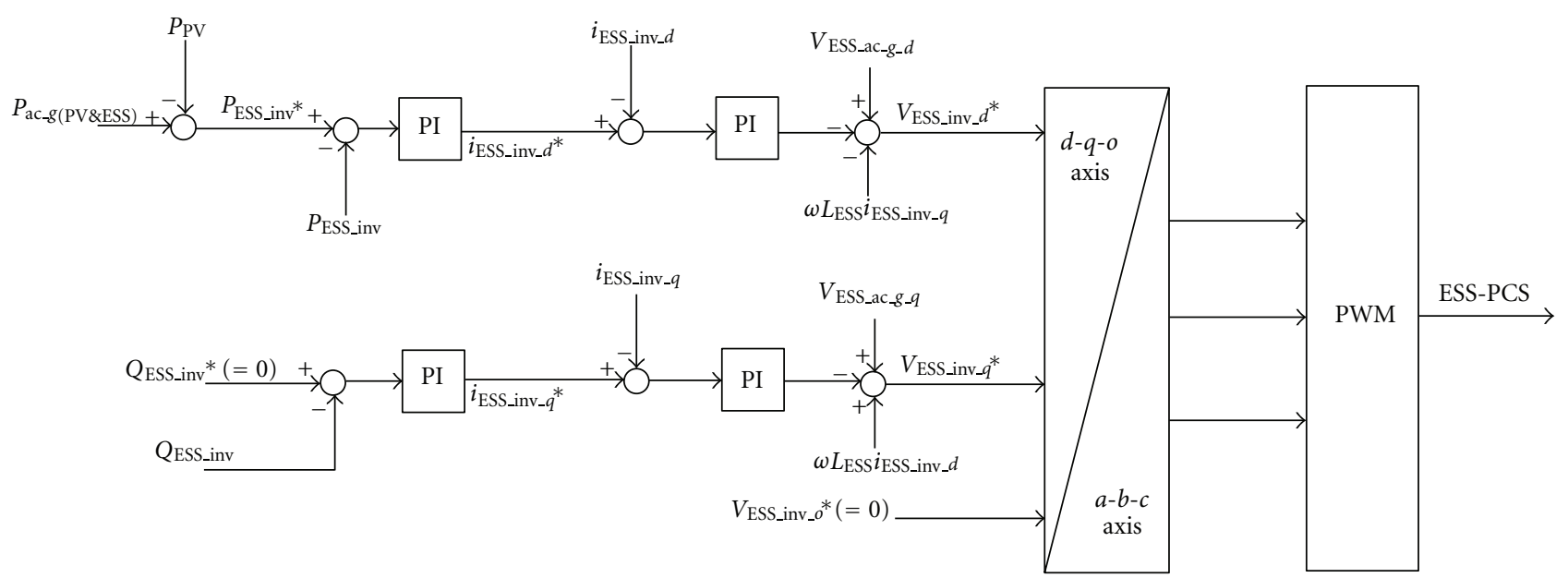

FIgURE 8: Conventional current control of ESS-PCS (ac connected PV-ESS hybrid system).

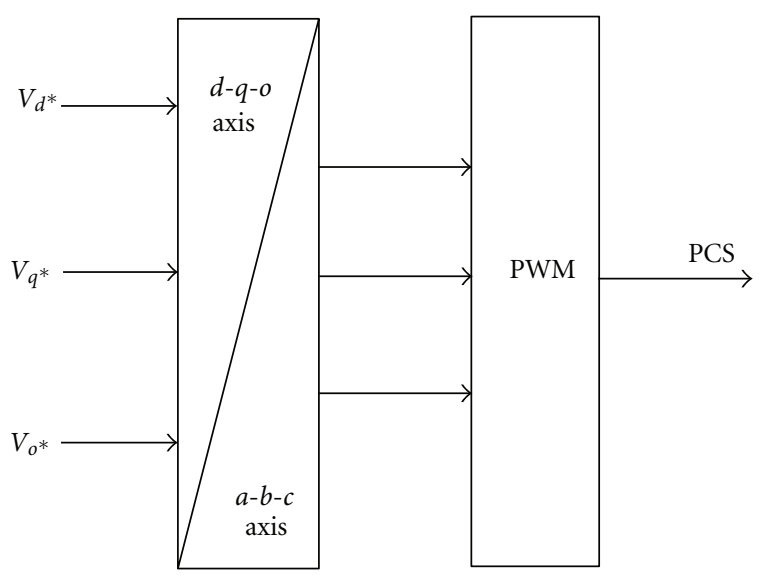

FIGURE 9: Constant voltage control of a dc-ac inverter (PV-PCS and ESS-PCS).

to the voltage control shown in Figure 9; this condition is defined in case (3). In this situation, the PV-PCS can be operated in the same manner as the normal condition, that is, in the power and current control manner in case (3).

\section{Proposed DC-Connected PV-ESS Hybrid System}

4.1. Modeling. Installation of energy storage system at the PV power station is found to be useful for output fluctuation suppression in normal condition and generation loss salvage during a fault. Usually, an energy storage system is connected in parallel to the PV arrays at the ac-side through individual dc-ac inverter. However, this ac connection has the following disadvantages.

(i) For the charging operation, the power generated by PV arrays must be converted twice by dc-ac inverters for PV arrays and storage device. It depresses total efficiency. (ii) The energy storage system cannot be used when the ac voltage drops due to a fault occurrence.

Figure 10 shows the circuit configuration of the dcconnected PV-ESS hybrid system. As shown in Figure 10, the PV arrays are directly connected to the dc-link and the ESS is also connected to the same dc-link through a bidirectional dc-dc converter which consists of two diodes, two self-turn-off switching devices, and a reactor. Note that the ESS's internal voltage must be larger than the possible open-circuit voltage of PV arrays to realize the bidirectional dc-dc converter current.

4.2. Proposed Control System for Bidirectional dc-dc Converter. As shown in Figure 11, the common dc-ac inverter for PV system is controlled to convert specified real and reactive powers by means of the conventional current controller. In Figure $11, i_{\text {inv_d }}{ }^{*}$ could be defined for total system output power in dc-connected PV-ESS hybrid system. The $i_{\text {inv_d }}{ }^{*}$ specified to 236[A] for common PV-PCS output power is $110.4[\mathrm{KW}]$; it is referred to discharging power 10 [KW] from ESS. On the other hand, the dc-dc converter for ESS device regulates the dc-link voltage to follow the voltage defined by the MPPT algorithm as shown in Figure 12. More specifically, the reference for ESS output current $\left(i_{\mathrm{ESS}}{ }^{*}\right)$ is obtained by passing the MPPT voltage error through a PI controller. Then, the error of $i_{\mathrm{ESS}}$ is used as an input signal for a hysteresis loop to generate the switching signals. By this control system, the ESS acts as a slack device at the dc-link. That is, when the PV arrays output is larger than the common dc-ac inverter (PV-PCS) power, the ESS system automatically absorbs (charges) the redundant power. On the contrary, the PV array output smaller than the common $\mathrm{dc}$-ac inverter (PV-PCS) power is automatically compensated by supply (discharge) from the ESS. The proposed control schemes can realize the followings functions.

(i) Since the dc-ac inverter (PV-PCS) converts specified constant power, the fluctuation in PV array output can be automatically suppressed by the ESS. 


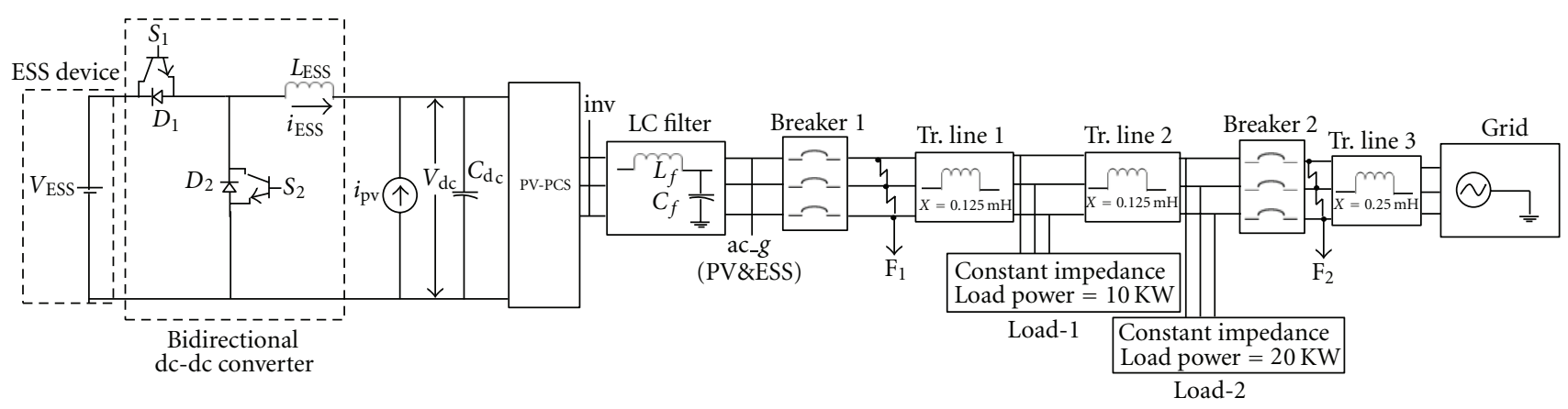

FIGURE 10: Circuit configuration of the dc connected PV-ESS hybrid system.

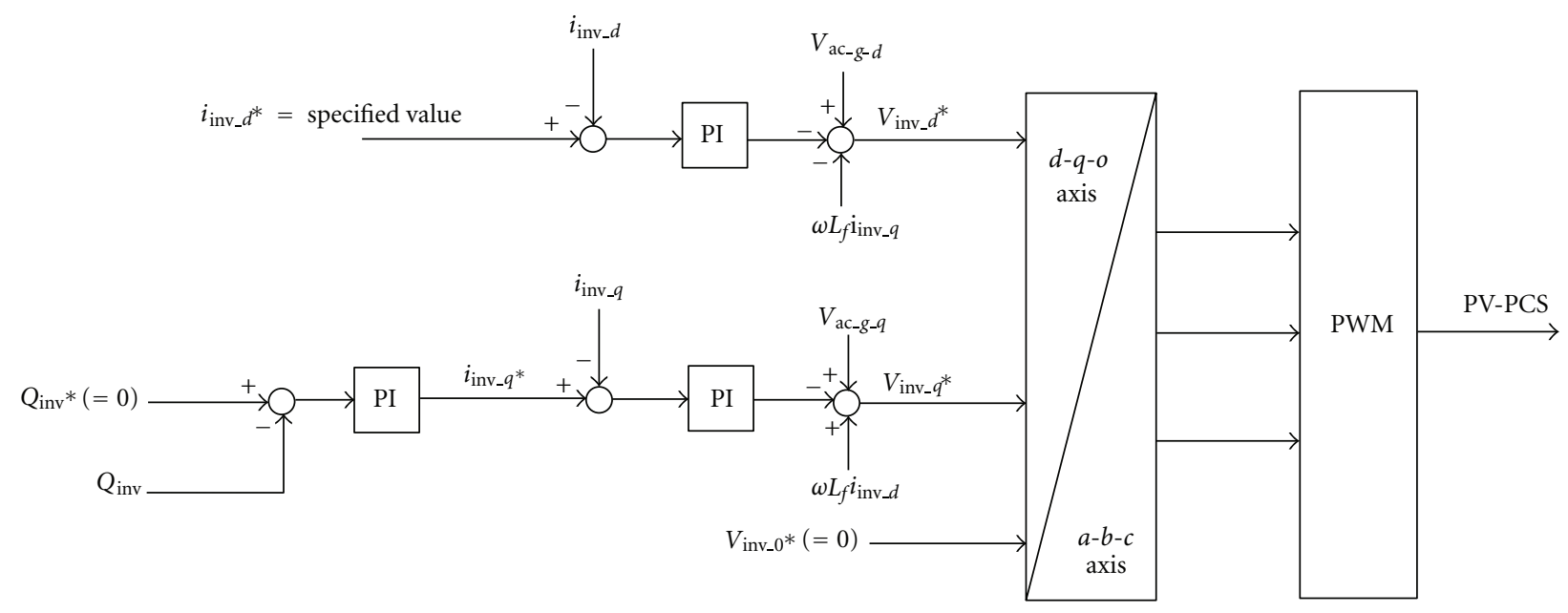

FIGURE 11: Control system for dc-ac inverter in dc-connected PV-ESS hybrid system.

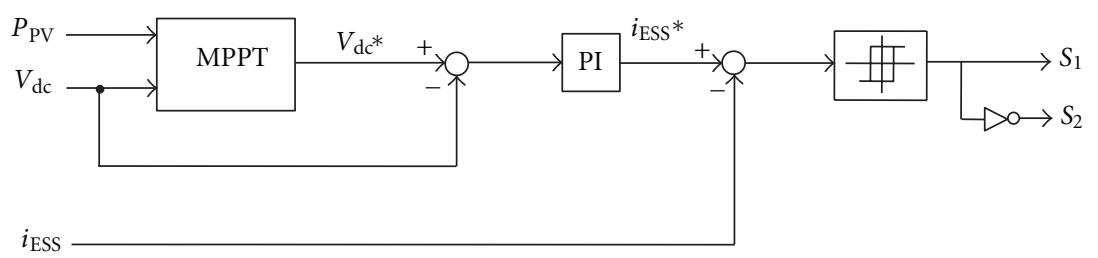

Figure 12: Control system for dc-link voltage in bidirectional dc-dc converter.

(ii) When a fault occurs at the main grid and the dc-ac inverter loses its converting ability, all of PV array outputs are automatically charged by the ESS. That is, the loss of generation can be avoided.

\section{Microgrid Concept in PV-ESS Hybrid Systems}

Figures 6 and 10 are shown the circuit configurations of the microgrid concept in ac-connected and dc-connected PVESS hybrid systems. These two systems (PV and ESS systems) feed the local loads named Load-1 and Load- 2 connected at the one-fourth and midpoint of the transmission line length, respectively; when the total PV-ESS output is larger than the local loads, the surplus energy is absorbed by the utility grid in both circuit configurations.
The auxiliary device breaker2 is installed for case (5) in Figure 6 and Figure 10. As described in Section 2.2 threephase to ground fault started time and detected time are same. A three-phase to ground fault $\left(\mathrm{F}_{2}\right)$ occurred at the middle point of the transmission line and breaker2 is used to disconnect the PV and ESS systems with the local loads from the faulted main grid at the fault detected time. It established an isolated local system. As a result, the disconnected components form an isolated system. PV and ESS power can be supported to local loads.

For ac-connected PV-ESS hybrid system, in order to govern the ac-side voltage (supply voltage to the local loads) in the isolated system, this paper employs the ESS-PCS as voltage source. Therefore, control mode for ESS-PCS should be immediately changed from the current control to voltage 


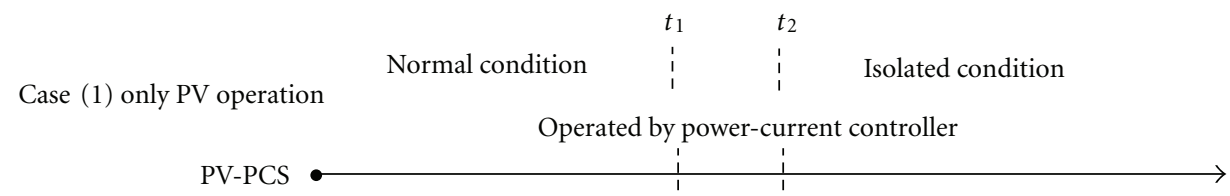

Case (2) ac-connected PV-ESS hybrid system

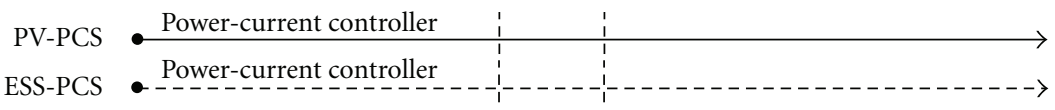

Case (3) ac-connected PV-ESS hybrid system

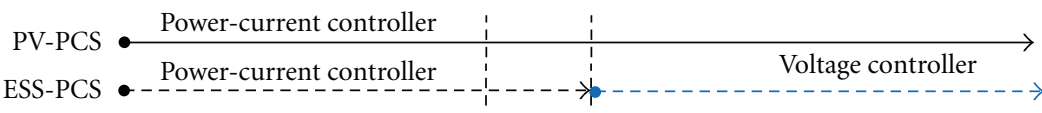

Case (4) dc-connected PV-ESS hybrid system

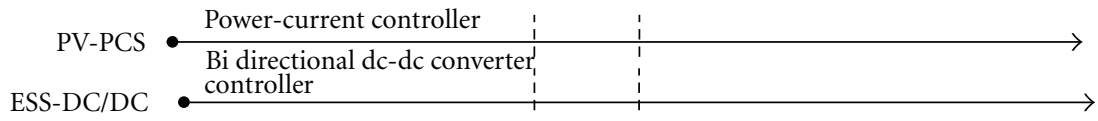

Case (5) microgrid concept in both connection types of PV-ESS hybrid system

AC-connected PV-ESS

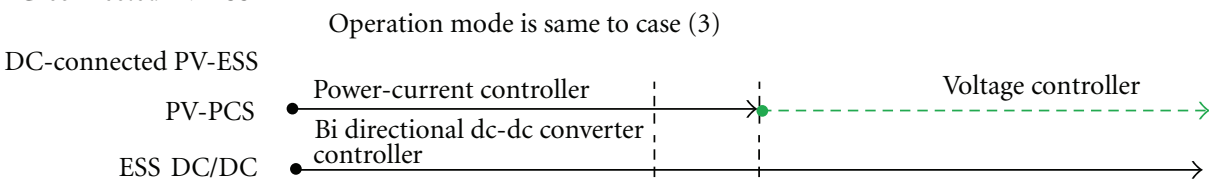

Figure 13: Operation mode.

control shown in Figure 9 at fault detected time. Since the ac-grid voltage in the isolated system is governed by the ESS-PCS, the PV-PCS can employ the same current control strategy even in the isolated operation mode.

For the isolated operation in dc-connected ESS hybrid after the fault detected time, on the other hand, operation mode of the common PV-PCS should be changed from current control mode to voltage control mode shown in Figure 9. However, the same control system can be applied to the dc-dc converter. As a result, PV power can be supplied supplied to the local loads. These control parameters of all control systems of hybrid PV-ESS systems in computational simulation are investigated by trial and error method. All of the cases of the operation mode are shown in Figure 13.

\section{Simulation Results}

6.1. Output Smoothing Condition in PV-ESS Hybrid Systems. The PV array generation, the ESS output, and the total system output measured at the ac-side of ac-connected and dc-connected PV-ESS hybrid systems are shown in Figures 14 and 15, respectively. Here, the solar irradiation level was assumed to vary from $1.0\left[\mathrm{~kW} / \mathrm{m}^{2}\right]$ to $0.5\left[\mathrm{~kW} / \mathrm{m}^{2}\right]$ at $1[\mathrm{sec}]$. According to the variation in solar irradiation, the maximum power from PV array also changes from 100.4 [kW] to 50.2
$[\mathrm{kW}]$. Therefore total system output power could achieve the same PV power as a previous condition although a solar radiation level is varied at 1 [sec]. As shown in these simulation results, we can say that both ac-connected and dc-connected PV-ESS hybrid systems can realize the output smoothing effectively. In other words, we can say that the typical connected system and dc-connected PV-ESS hybrid system shows almost same performance in output smoothing function.

6.2. Salvage of Generation Loss in PV-ESS Hybrid Systems. Behavior of the both circuit configurations were also performed in the condition of simulation. In ac-connected PVESS hybrid system, the ESS cannot support the PV array output after the fault occurrence; that is, the dc-link voltage rises to the open-circuit voltage of PV array and, as a result, the PV array generation output closely becomes zero in Figure 16. But if the ESS-PCS is controlled in voltage-control manner as shown in Figure 17, the ESS-PCS supported the ac voltage after the breaker (Breaker1) operation; as a result, the PV-PCS could work to regulate dc-link voltage as usual and the PV array generation output could be obtained, but this observation indicates that the generation loss during a fault could not be salvaged by the ESS in Figure 17 in acconnected PV-ESS hybrid system. The dc-link voltage was increased from fault started time to detected time. 


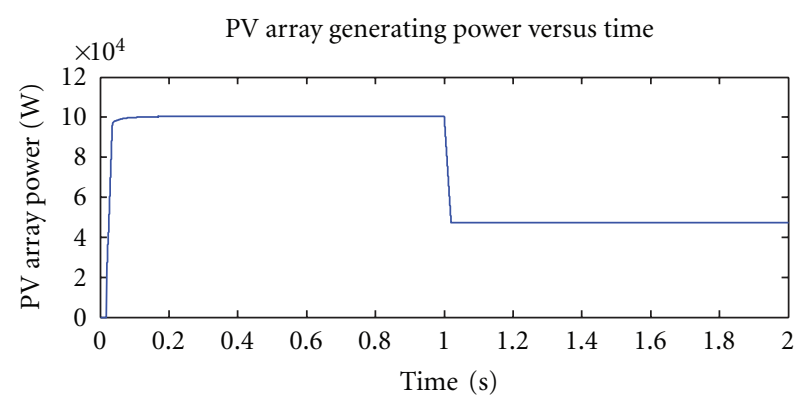

(a) PV array generating power output

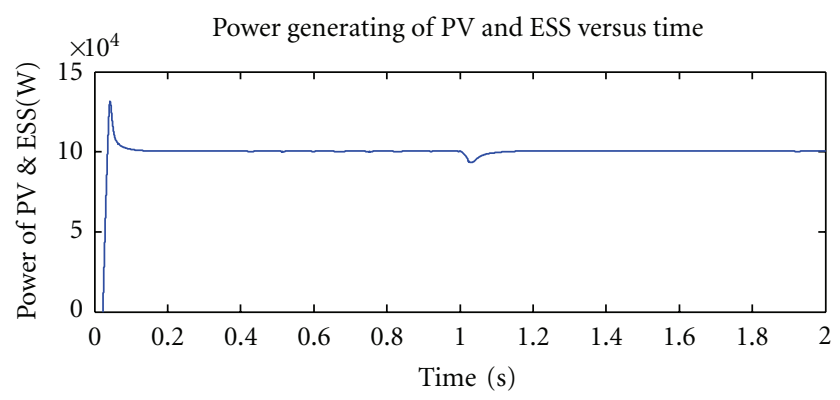

(b) Total system output

FIGURE 14: PV output smoothing by ac-connected PV-ESS hybrid system.

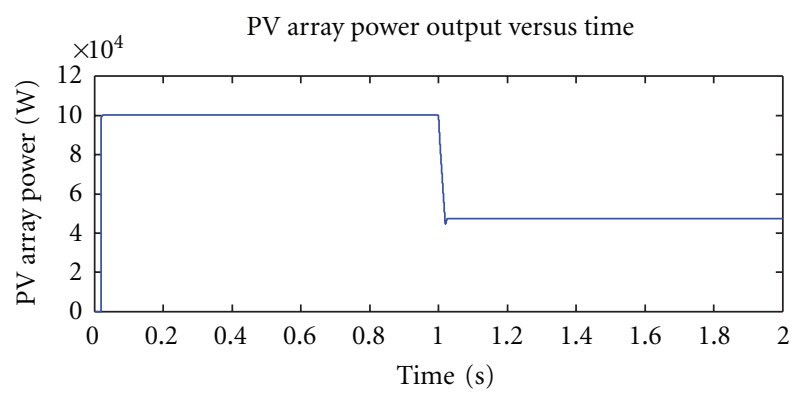

(a) PV array generation power output

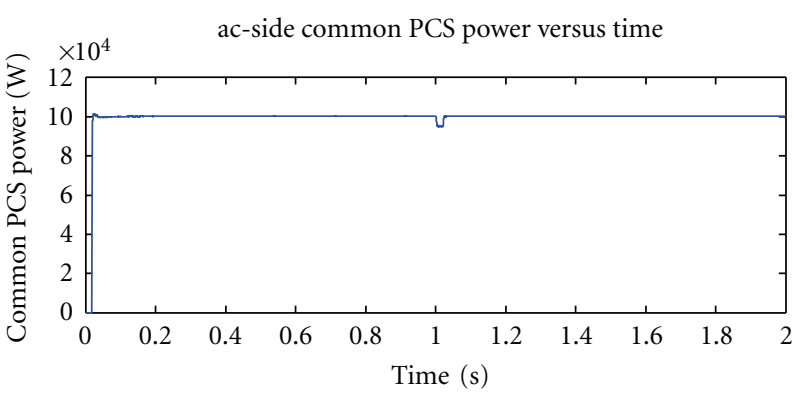

(b) Common PCS power (measured at ac-side)

FIGURE 15: PV output smoothing by dc-connected PV-ESS hybrid system.

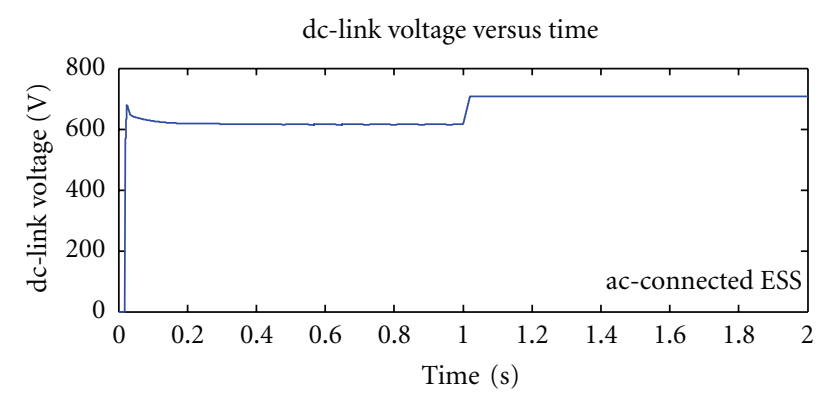

(a) dc-link voltage (case 2)

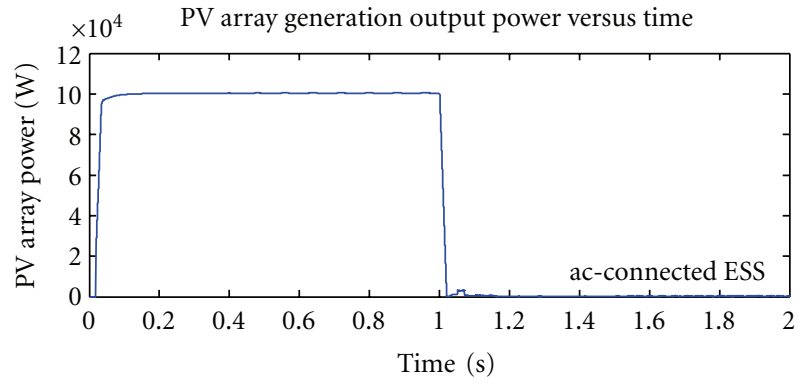

(b) PV array generation output (case 2)

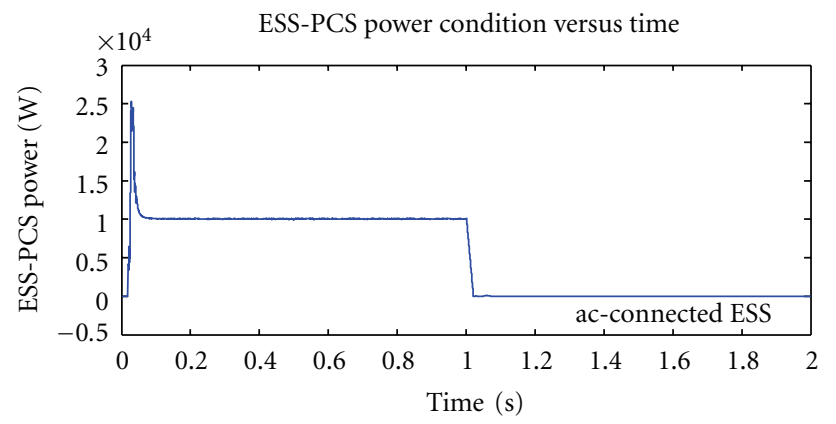

(c) ESS-PCS output (case 2)

FIGURE 16: Behavior of ac-connected PV-ESS hybrid (case 2). 


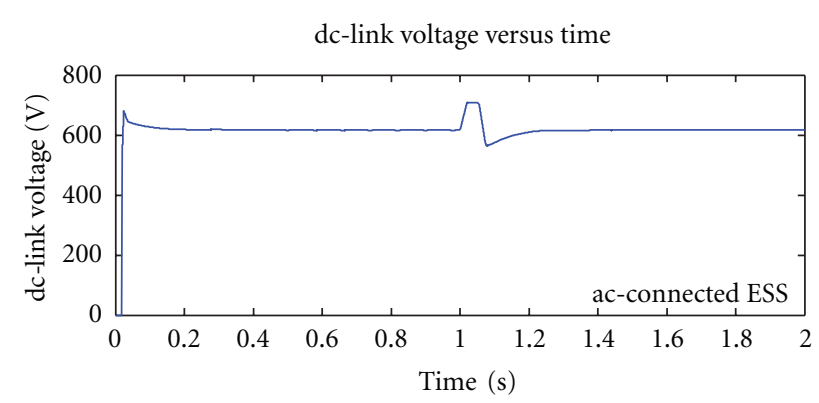

(a) dc-link voltage (case 3)

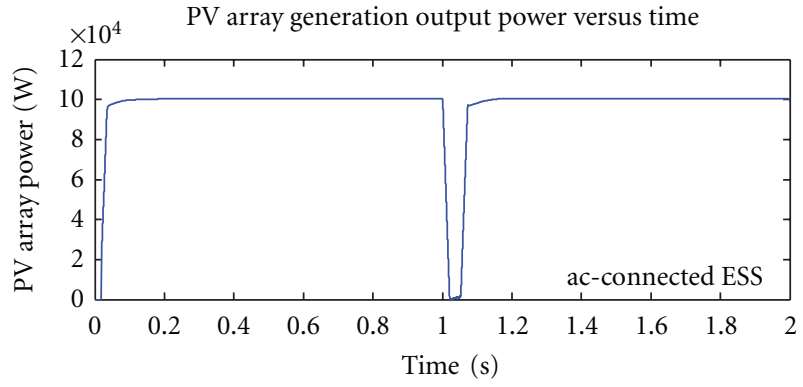

(b) PV array generation output (case 3)

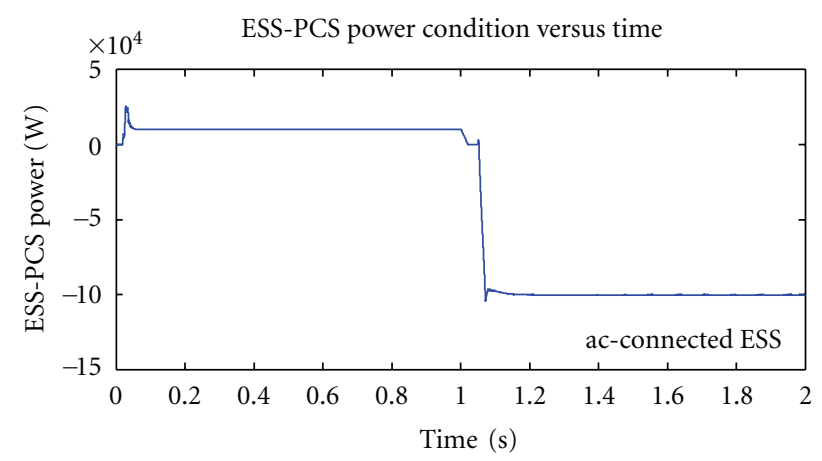

(c) ESS-PCS output (case 3)

FIgURE 17: Behavior of ac-connected PV-ESS hybrid system under the faulted condition (case 3).

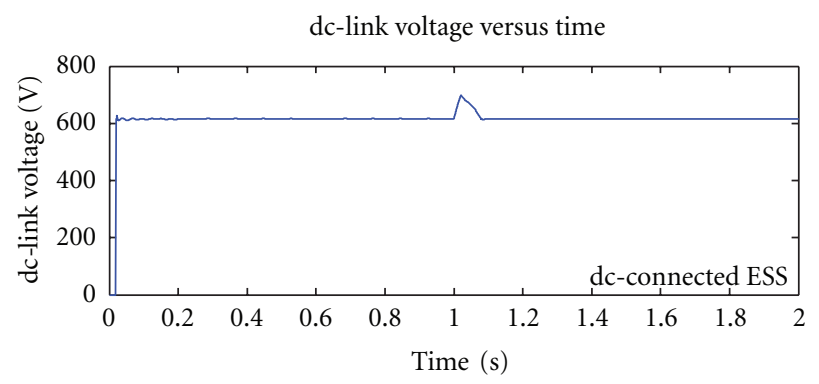

(a) dc-link voltge (case 4)

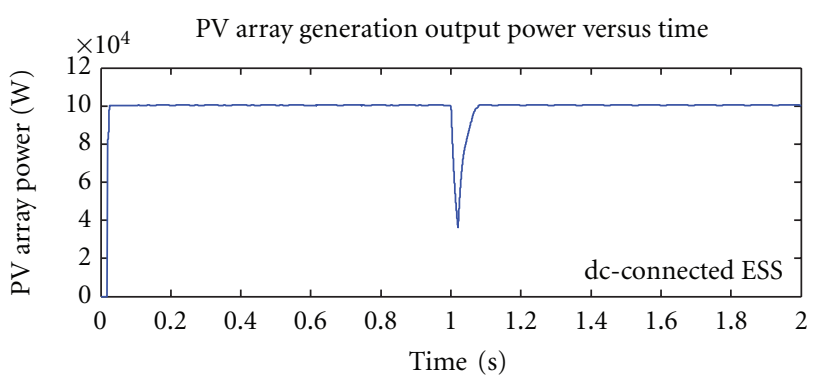

(b) PV array generation output (case 4)

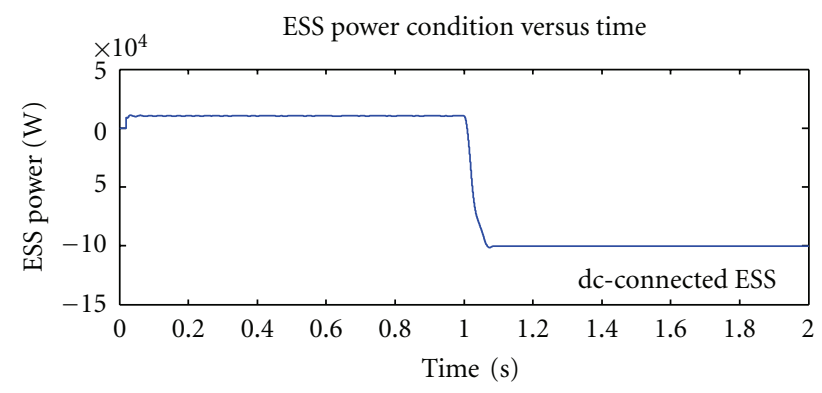

(c) ESS output (case 4)

Figure 18: Behavior of dc-connected PV-ESS hybrid system under the faulted condition (case 4).

The simulation results for the dc-connected PV-ESS hybrid system are shown in Figure 18, indicating that the dclink voltage did not increase until the open-circuit voltage of PV array with the help of ESS's dc-dc converter and dc-link voltage is compensated by $\mathrm{dc}-\mathrm{dc}$ converter during fault condition. Therefore, the dc-connected PV-ESS hybrid system could enter to the isolated operation mode seamlessly and less generation loss was achieved. However we can conclude 


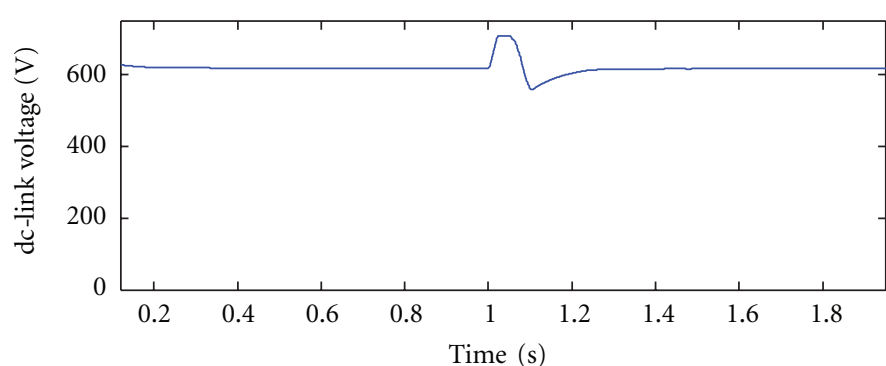

(a) dc-link voltage (case 5)

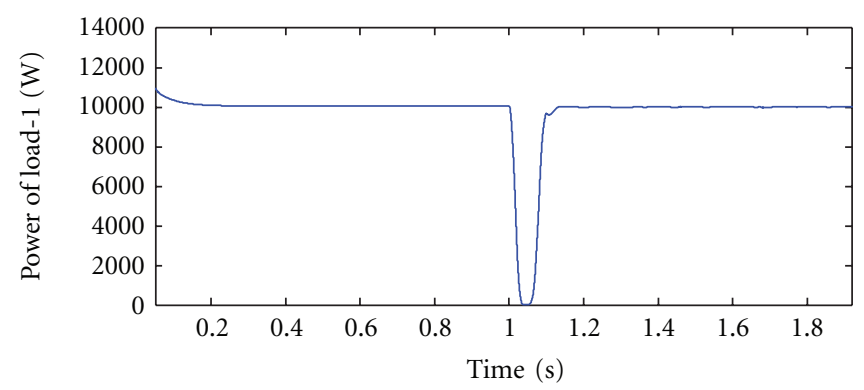

(c) Power of load-1 (case 5)

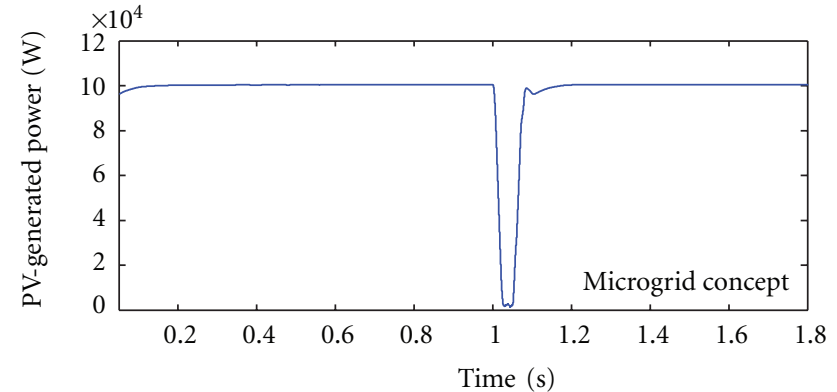

(b) PV array generation output (case 5)

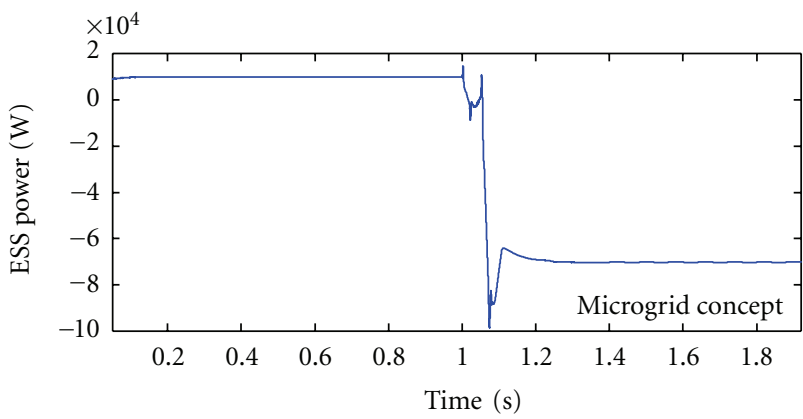

(d) ESS power (case 5)

FIGURE 19: Behavior of microgrid concept in ac-connected PV-ESS hybrid system (case 5).

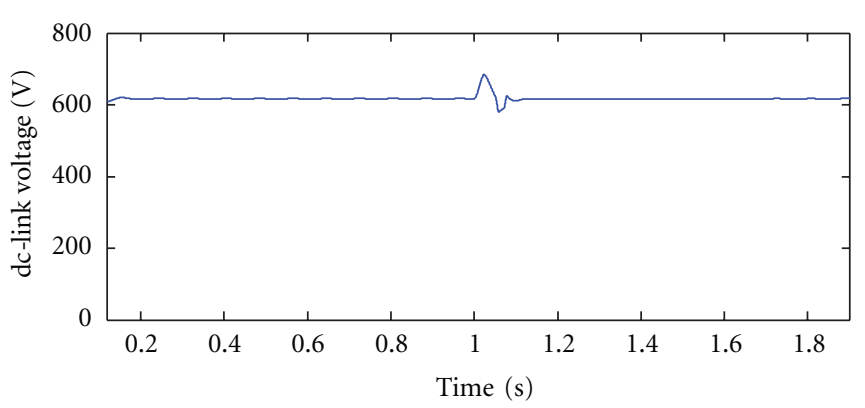

(a) dc-link voltage (case 5)

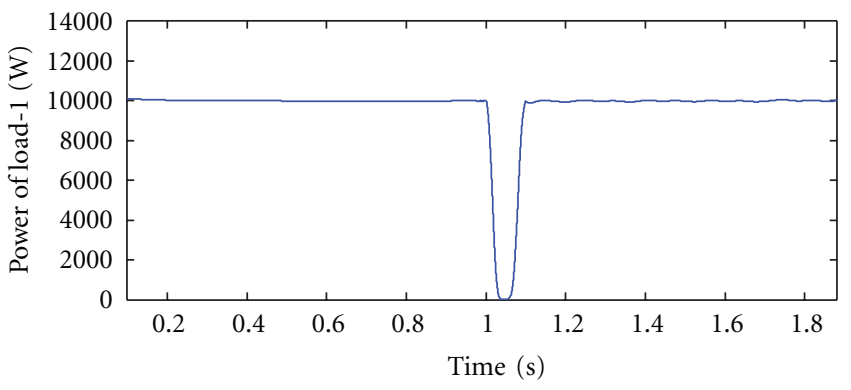

(c) Power of load-1 (case 5)

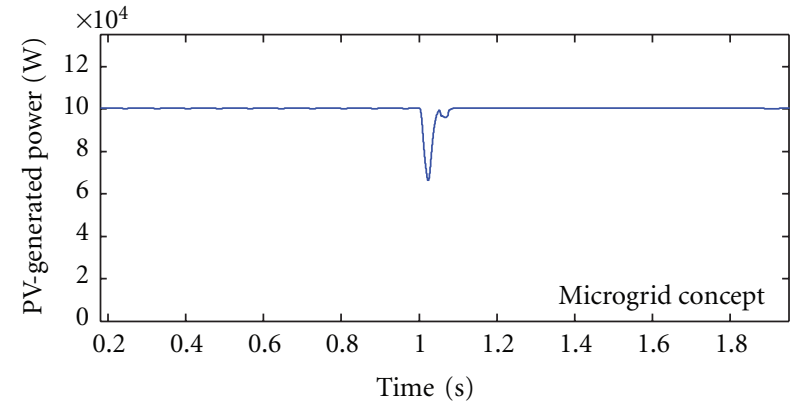

(b) PV array generation output (case 5)

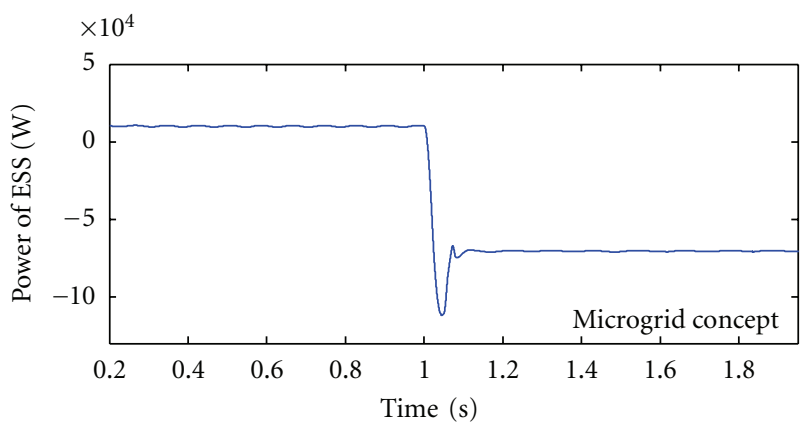

(d) ESS power (case 5)

Figure 20: Behavior of microgrid concept dc-connected PV-ESS hybrid system (case 5).

the merit of hybridization of PV and ESS from the view point of power salvage during the fault. This comparison results pick up from case 1 to case 4 , and three-phase to ground fault $\left(F_{1}\right)$ occurred at the sending terminal of the transmission line. This merit condition is presented in Figure 21.
6.3. Demand and Supply Balancing of Microgrid Concept in PV-ESS Hybrid System. As simulation results of acconnected PV-ESS, dc-link voltage, PV array output power, local load-1 consuming power, and ESS output power are shown in Figures 19(a), 19(b), 19(c), and 19(d), respectively. 


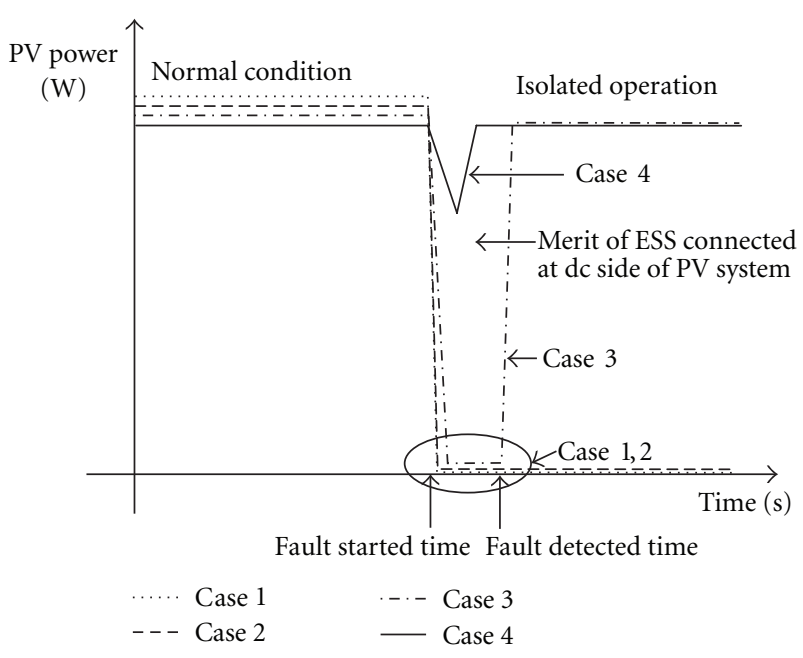

FIGURe 21: Merit of hybrid systems from the view point of PV power salvage during a fault.

During faulted condition, the ESS-PCS cannot work also; therefore, PV generation losses during the fault are unavoidable in this case. The power balance at the dc-link is broken and the dc-link voltage rises to the open-circuit voltage of the PV array in Figure 19(a); consequently the PV output power drops to nearly zero as shown in Figure 19(b) in during fault condition. PV-PCS is operated by conventional current controller continuously, and the operated controller of ESS-PCS should be changed from current controller mode to voltage controller mode. As a result, PV power could be supported to two local loads; load-1 result is shown in Figure 19(c) and its excess power charge to ESS in Figure $19(d)$ in isolated condition.

For dc-connected ESS hybrid system, the simulation results of dc-link voltage, PV array output power, and local load-1 consuming power and ESS output power are shown in Figures 20(a), 20(b), 20(c), and 20(d), respectively. The conventional current control system of PV-PCS is changed to constant voltage controller at fault detected time in dc-connected PV-ESS hybrid system. However, the rise in the dc-link voltage is rapidly compensated by the ESS in Figure 20(a); therefore, generation losses associated with the fault occurrence can be mitigated in Figure 20(b). This PV output loss salvage function is one of the advantages of proposed dc-connected ESS. PV power could be supported to local loads and ESS in Figure 20 and Figure 21 in isolated condition.

\section{Conclusion}

This paper proposed the dc-connected PV-ESS hybrid system and its control strategies for three functions, smoothing function in normal condition, PV generation loss salvage during faulted condition, and supply and demand balancing in isolated operation. The technical feasibility of the proposed system and control strategies were investigated though the computational simulations on Matlab/Simulink environment. Furthermore, the performance of proposed system was compared quantitatively with the conventional ac-connected PV-ESS hybrid system. Results from the computational simulations revealed that the proposed system showed almost same performances in the smoothing function and the isolated operation and was superior in the power salvaging function, in comparison to the conventional acconnected PV-ESS hybrid system.

\section{References}

[1] R. Hara, H. Kita, T. Tanabe, H. Sugihara, A. Kuwayama, and S. Miwa, "Demonstration grid-connected photovoltaic projects in Japan," in Proceedings of the IEEE Power and Energy Magazine, pp. 77-85, June 2009.

[2] M. Akatsuka, R. Hara, H. Kita et al., "Analysis of fluctuation of PV power plant output with energy storage system," in Proceedings of the 24th European Photovoltaic Solar Energy Conference, no. 5BV.2.30, pp. 4123-4126, 2009.

[3] M. Akatsuka, R. Hara, H. Kita, T. Ito, Y. Ueda, and Y. Saito, "Estimation of battery capacity for suppression of a PV power plant output fluctuation," in Proceedings of the 35th IEEE Photovoltaic Specialists Conference (PVSC '10), no. 135, pp. 540-543, June 2010.

[4] J. Xue, Z. Yin, B. Wu, Z. Wu, and J. Li, "Technology research of novel energy storage control for the PV generation system," in Proceedings of the Asia-Pacific Power and Energy Engineering Conference (APPEEC '09), March 2009.

[5] I. J. Balaguer, H. G. Kim, F. Z. Peng, and E. I. Ortiz, "Survey of photovoltaic power systems islanding detection methods," in Proceedings of the 34th Annual Conference of the IEEE Industrial Electronics Society (IECON '08), pp. 2247-2252, November 2008.

[6] G. M. Azevedo, G. Vazquez, A. Luna, D. Aguilar, and A. Rolan, "Photovoltaic inverters with fault ride-through capability," in Proceedings of the IEEE International Symposium on Industrial Electronics (ISIE '09), pp. 549-553, July 2009.

[7] M. Dali, J. Belhadj, and X. Roboam, "Hybrid Solar-wind system with battery storage operating in grid-connected and stand alone mode: control and energy management-experimental investigation," Energy, vol. 35, no. 6, pp. 2587-2595, 2010.

[8] Takahashi, K. Kawasaki, and T. Matsunobu, "The characteristics of surge current by lightning strike and counter-measure against lightning strike on photovoltaic system," in Proceedings of the Institute of Electrical Engineers, vol. 109, no. 10, pp. 443450, 1989.

[9] N. Fujimura, M. Kurokawa, K. Kawasaki, and K. Kawasaki, "The analysis of loss on photovoltaic system," National Convention of Institute of Electrical Engineers, pp. 11-135, 1989.

[10] S. K. Kim, J. H. Jeon, C. H. Cho, E. S. Kim, and J. B. Ahn, "Modeling and simulation of a grid-connected PV generation system for electromagnetic transient analysis," Solar Energy, vol. 83, no. 5, pp. 664-678, 2009.

[11] Y. Jung, J. So, G. Yu, and J. Choi, "Improved perturbation and observation method (IP\&O) of MPPT control for photovoltaic power systems," in Proceedings of the 31st IEEE Photovoltaic Specialists Conference, pp. 1788-1791, January 2005. 

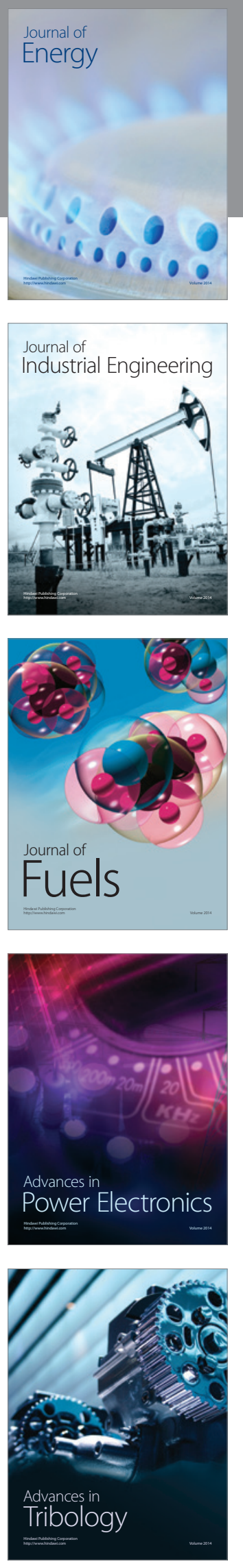
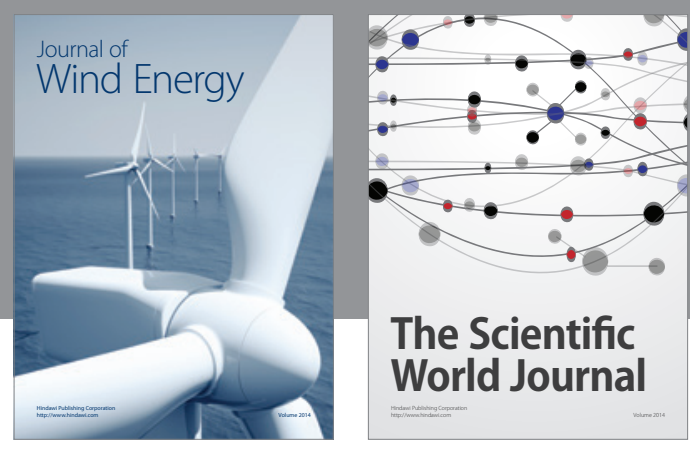

The Scientific World Journal

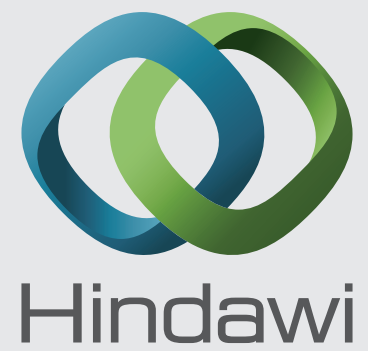

Submit your manuscripts at http://www.hindawi.com
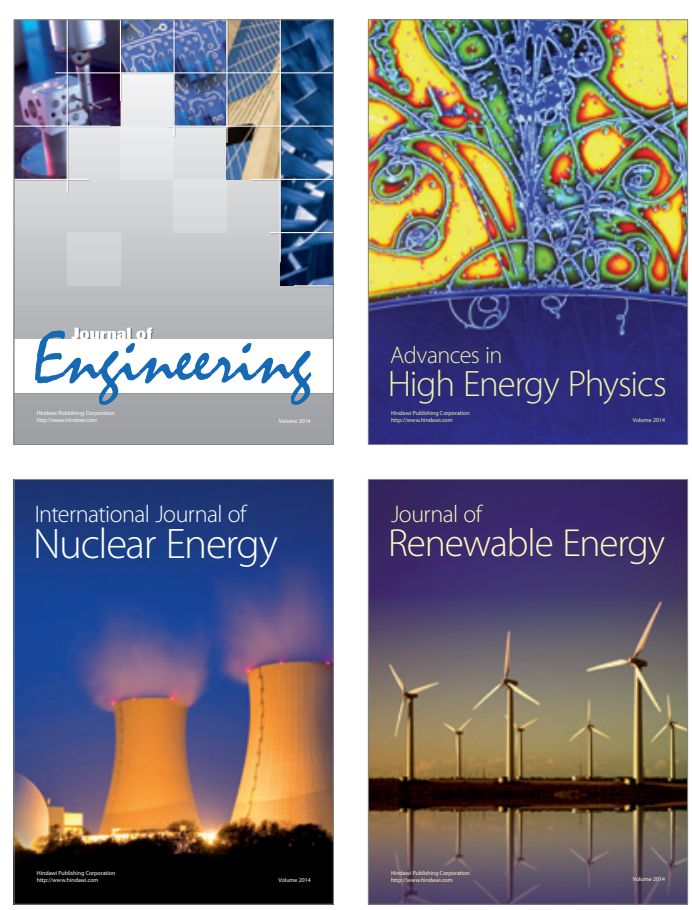

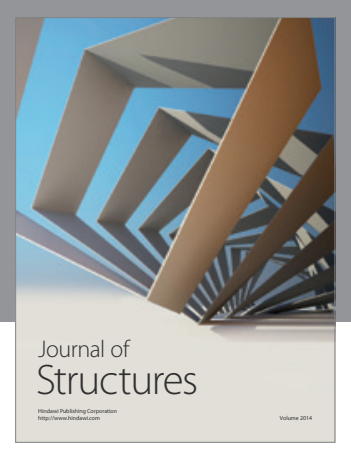

Rotating
Mechinery
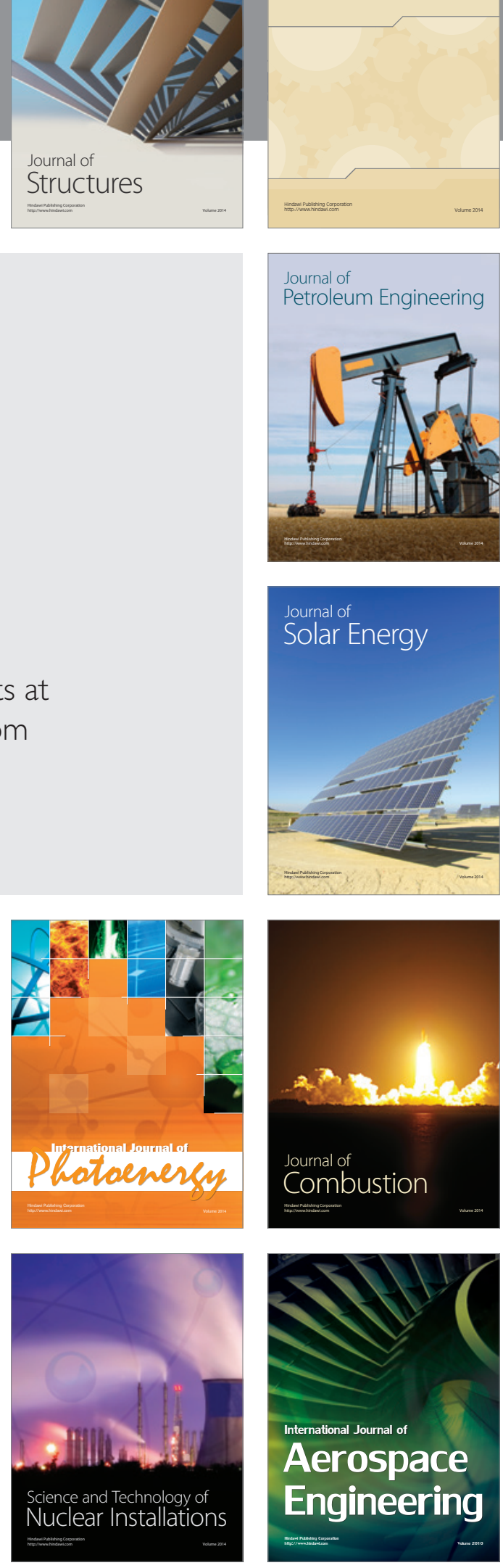